\title{
Influence of Welding Parameters on Optimization of the Tensile Strength and Peak Temperature in AISI 1020 Alloy Joints Welded by SAW
}

\author{
Raad Jamal Jassim ${ }^{1, b}$, Haider Mahdi Lieth ${ }^{1, \mathrm{c}}$, Raheem Al-Sabur ${ }^{1, a)}$ and Ahmad \\ Alsahlani ${ }^{1, \mathrm{~d}}$ \\ ${ }^{1}$ University of Basrah, Mechanical Engineering Department, Basra 61001, Iraq \\ ${ }^{a)}$ Corresponding author: raheem.musawel@uobasrah.edu.iq \\ b) raad.jassim@uobasrah.edu.iq \\ c) haider.lieth@uobasrah.edu.iq \\ d) ahmad.mahdi@uobasrah.edu.iq
}

\begin{abstract}
Submerged Arc Welding (SAW) is a safe and efficient process for joining thick plates AISI 1020. A high-quality weld joint is a critical objective in a series of optimization studies. The current study focuses on maximizing the ultimate tensile strength and minimizing the peak temperature using Taguchi, Genetic Algorithm (GA), and Simulated Annealing (SA) algorithms. The input parameters in the three techniques were voltage (V), welding speed (S), and wire feed rate (F). At a 95\% confidence level, the regression models were combined using the ANOVA to predict tensile strength and peak temperature. The maximum ultimate tensile strength was $599 \mathrm{MPa}$ achieved at a welding speed of $30 \mathrm{~mm} / \mathrm{s}$, an arc voltage of $30 \mathrm{~V}$, and a wire feed rate of $120 \mathrm{~mm} / \mathrm{s}$, while the minimal peak temperature was $417 \mathrm{C}$ under the same conditions. With the increase of the welding parameters (welding speed, arc voltage, and feed rate), the ultimate tensile strength was increased. Furthermore, the average hardness achieved was 250 at welding metal and 292 at HAZ, while it was 275 at the base metal. The results were supported with an examination of microstructure. In the heat-affected zone (HAZ), the grain was finer while its grain size was larger in specimens with high tensile strength. It was noticed that the HAZ contains pearlite and some colonies of ferrite.
\end{abstract}

\section{INTRODUCTION}

Submerged arc welding is an automatic or semiautomatic fusion process, particularly appropriate for welding the thick plates required for many industrial applications [1]. In this process, heat generated between the workpiece and the consumable electrode is fed continuously from a wire electrode roll, which is quite enough to produce the welding arc. A type of granular flux is used to protect the welding region, reduce the cooling rate and heat energy losses, and prevent most welding defect types [2]. In recent decades, the development of the surface and mechanical properties for AISI 1020 low-carbon steel has been studied as they are commonly used in engineering applications, especially in welding applications [3]. AISI 1020 has low tensile strength, low hardenability properties, and good weldability. The optimization techniques play a pivotal role in finding the optimum welding parameters for improving the mechanical properties, whether they be fusion or solid-state welding processes $[4,5]$. The most widely used techniques in welding optimization are Response Surface Methodology (RSM), Artificial Neural Networks (ANN), Taguchi method, simulated annealing, genetic algorithm, regression analysis, and Monte-Carlo simulation, amongst others. This study then focuses on three methods: Taguchi, Genetic Algorithm (GA), and Simulated Annealing (SA). Each method aims to optimize the welding variables to maximize the tensile strength and minimize the peak temperature during submerged arc-welding processes. 
For ASTM A516 grade 70 low carbon plates of steel welded by SAW, it was found that the ultimate tensile was achieved at an arc voltage of $36 \mathrm{~V}$, a welding current of $400 \mathrm{~A}$, and a welding speed of $30 \mathrm{~cm} / \mathrm{min}$ using the Taguchi method (L9) in correspondence with the signal-to-noise ratio $(\mathrm{S} / \mathrm{N})$. The study here indicated that the welding parameters used to achieve ultimate tensile strength were different from the parameters for maximum hardness value. The influence of the welding speed and the arc voltage on the mechanical properties was found to be much lower than for the current process [6]. Taguchi's orthogonal array was also used for optimizing the penetration and the tensile strength of the low-temperature service pressure vessels welded by SAW. According to the S/N ratio, for the alloy ASTM A516 Gr.7 used, the maximum tensile strength of $455 \mathrm{MP}$ was obtained at $29 \mathrm{~V}$ voltage, $0.2 \mathrm{~m} / \mathrm{min}$ welding speed, and a wire-feed rate of $5.5 \mathrm{~m} / \mathrm{min}$ [7]. The same Taguchi design was used for finding optimum tensile strength of carbon steel SA 516 grade 70 . The optimal conditions resulted in a $34 \mathrm{~V}$ voltage, which was the most significant factor, along with a $475 \mathrm{~A}$ current, and $30 \mathrm{~cm} / \mathrm{min}$ welding speed [8]. The study was then expanded to find the optimum microstructure and hardness in the welding zone and heat-affected zone regions.

The Taguchi optimization principle was used to investigate process parameters of SAW low-carbon steel joints. Three process parameters were taken into consideration as input parameters (electrode stick-out, wire feed, and welding speed) where the response parameters, such as toughness, the strength of tensile, and hardness, were considered as output parameters [9]. On the other hand, heat generation takes place during the SAW process itself, which increases the temperature of the welded plate. Taguchi's OA L9 was thus employed to investigate the temperature of the welded plate, while an infrared thermometer was used for temperature measuring. A maximum temperature of $3240^{\circ} \mathrm{C}$ was achieved at a welding current of $600 \mathrm{~A}$, a voltage of $32 \mathrm{~V}$, a standoff distance of $25 \mathrm{~mm}$, and a welding speed of $175 \mathrm{~mm} / \mathrm{min}$ [10]. An experimental investigation concentrated on the control variables and process responses of A36 carbon steel joints welded by SAW and based on the Taguchi orthogonal array. The results obtained showed that the strength of tensile was inversely proportional to current, voltage, and welding speed, while the peak temperature was raised in accordance with the increase in current, which was then decreased by voltage and the increasing welding speed [11].

Regarding the genetic algorithm, a comparative study of low-carbon steel states definitively that multi-objective GA may be used efficiently for the difficult optimization of ductility and strength in submerged arc-welded joints [12]. To minimize resource use in a windmill tower welded structure, one study investigated the suitability of the genetic algorithm to optimize the SAW parameters. The linear equation obtained from the regression and RSM model was then fed into the genetic algorithm to get a modified equation [13]. The results of the Taguchi L8 orthogonal array were used to minimize the weld bead width of the semi-automatic SAW joints by combining the resulting data with particle swarm optimization (PSO) and genetic algorithm (GA) tools [14]. The GA method is generally effective in solving the highly nonlinear equations, especially in predicting and optimizing the welding outputs [15].

For the third technique, a simulated annealing (SA) algorithm - and sometimes adaptive simulated annealing - was widely used to search the optimal process parameters of many welding processes such as SAW, friction stir welding, TIG welding, amongst others [16-19].

\section{METHODOLOGY}

\section{Taguchi Method}

Introduced in the 1940s, the Taguchi method has been traditionally utilized to conduct the submerged arc welding experiments. It is a method for systematically improving the quality that enables independent estimation for the output with minimal experimental runs $[20,21]$. Orthogonal array $(\mathrm{OA})$ and signal-to-noise ratio $(\mathrm{S} / \mathrm{N})$ are the main components of this method. An orthogonal array is used to find the optimum process parameters and reduce the variance. On the other hand, the $(\mathrm{S} / \mathrm{N})$ ratio is used to analyze the deviations of the expected values and assess process resilience. Three categories of signal-to-noise-ratio quality characteristics were then used in this study: smaller-isbetter, nominal-is-better, and larger-is-better.

\section{Genetic algorithm (GA)}

In the 1960s and 1970s, John Holland and his team introduced the genetic algorithm (GA) inspired by the natural

evolutionary process and then developed it for a wide range of applications until achieving multi-objective engineering optimizations [22]. Genetic algorithms, on the other hand, have significant drawbacks in terms of the selection of critical factors, the construction of the fitness function, and the usage of population size [23]. 


\section{Simulated Annealing (SA)}

While the genetic algorithm was taken from the natural biological evolution process, the simulated annealing algorithm was taken from the simulation of the thermodynamic process of annealing (gradual cooling of the molten metal to a solid-state) [24]. An iterative movement was used in the SA technique according to the variable temperature parameter that simulates the metal annealing transaction. This algorithm compares the outputs of the objective functions iteratively, running with the current and nearby points in the domain. Moreover, it saves the adjacent point as the basis solution for the next iteration, where the adjacent point provides a better result than the current one. Otherwise, the algorithm stops the procedure without looking for better results in a larger region [25].

The current study focuses on optimizing the strength of tensile and peak temperature according to the three process parameters: the voltage $(\mathrm{V})$, welding speed $(\mathrm{S})$, and the wire feed rate $(\mathrm{F})$. In turn, three optimization techniques are used for this purpose: the Taguchi method, genetic algorithm (GA), and simulated annealing (SA). The optimization results will be supported by microstructure and microhardness analysis.

\section{MATERIALS AND EXPERIMENTAL PROCEDURE}

Each of the welding performances were performed in the "NURIS SAW 800 make inverter-based" submerged arcwelding machine, equipped with a copper-coated steel electrode of $3.2 \mathrm{~mm}$. The chemical composition of the electrode is $\mathrm{Si} 0.01 \%$, Mn 1.1\%, C $0.08 \%$, which is compatible with AWS A5.17 EM12. A granulated flux of high silica gel was used as a shield for weld zone protecting from atmospheric contamination. The SAW machine is shown in figure 1 .

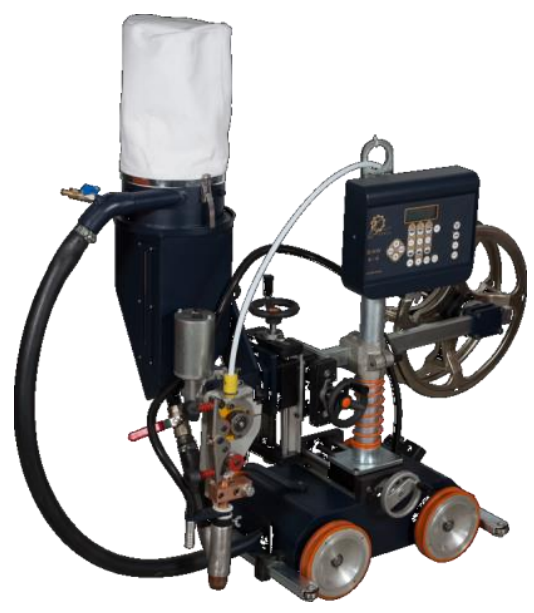

FIGURE 1. Experimental setup for submerged arc welding

The workpiece selected for submerged arc welding was an AISI 1020 rectangular shape with a dimension of 120x50x10. Table 1 shows the chemical composition of AISI 1020.

TABLE 1. Chemical Composition of AISI 1020

\begin{tabular}{cccccccc}
\hline Element & $\mathbf{C}$ & $\mathbf{M n}$ & $\mathbf{S i}$ & $\mathbf{C u}$ & $\mathbf{P}$ & $\mathbf{S}$ & $\mathbf{F e}$ \\
\hline$\%$ & 0.215 & 1.21 & 0.4 & 0.128 & 0.005 & 0.008 & Balanced \\
\hline
\end{tabular}

The welding was done on 27 pieces having dimensions of $120 \times 50 \times 10 \mathrm{~mm}$, with their surfaces then cleaned for oxides and contamination removal via sandblasting. Numerous tests were performed based on voltage, welding speed and wire feed rate. A portable thermocouple (K-type) of $1 \mathrm{~mm}$ diameter was used beside an infrared thermometer. The infrared thermometer was placed exactly below the welding arc and connected with an arm that can be moved in line with the same welding speed. The K-type thermocouples were inserted into the drilled holes to ensure perfect contact with the metal. The temperature was recorded at four different locations by the K-type thermocouple placed $2.4 \mathrm{~mm}$ away from each other from the central position along the transverse direction, as shown in Figure 2. 


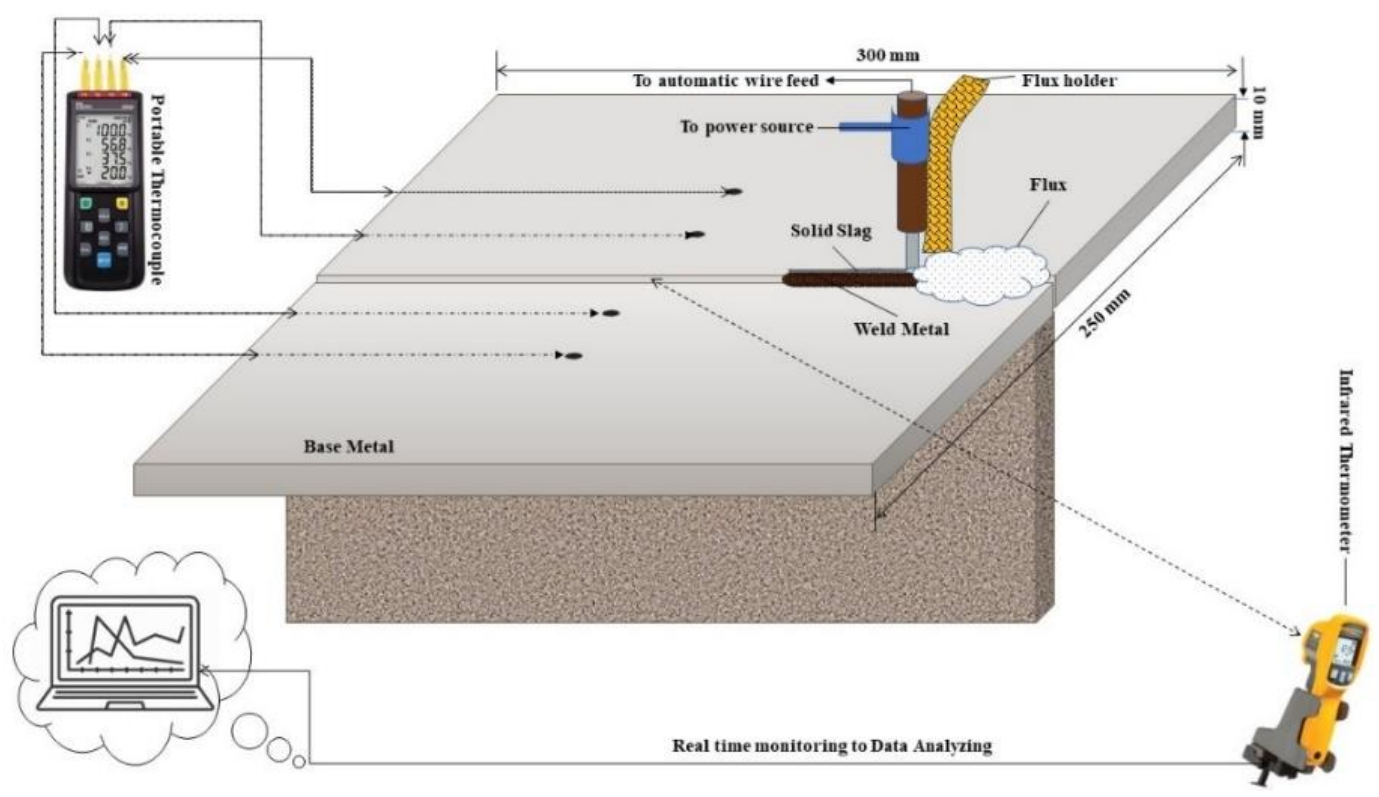

FIGURE 2. Scheme of temperature measuring in submerged arc welding

Welding speed, wire feed rate and arc voltage were the process parameters. Three levels for each parameter were considered after doing several experimental turns, as shown in Table 2. Taguchi OA L9 was used as a design matrix for optimizing the strength of tensile and the peak temperature in the welding region, as is shown in Table 3.

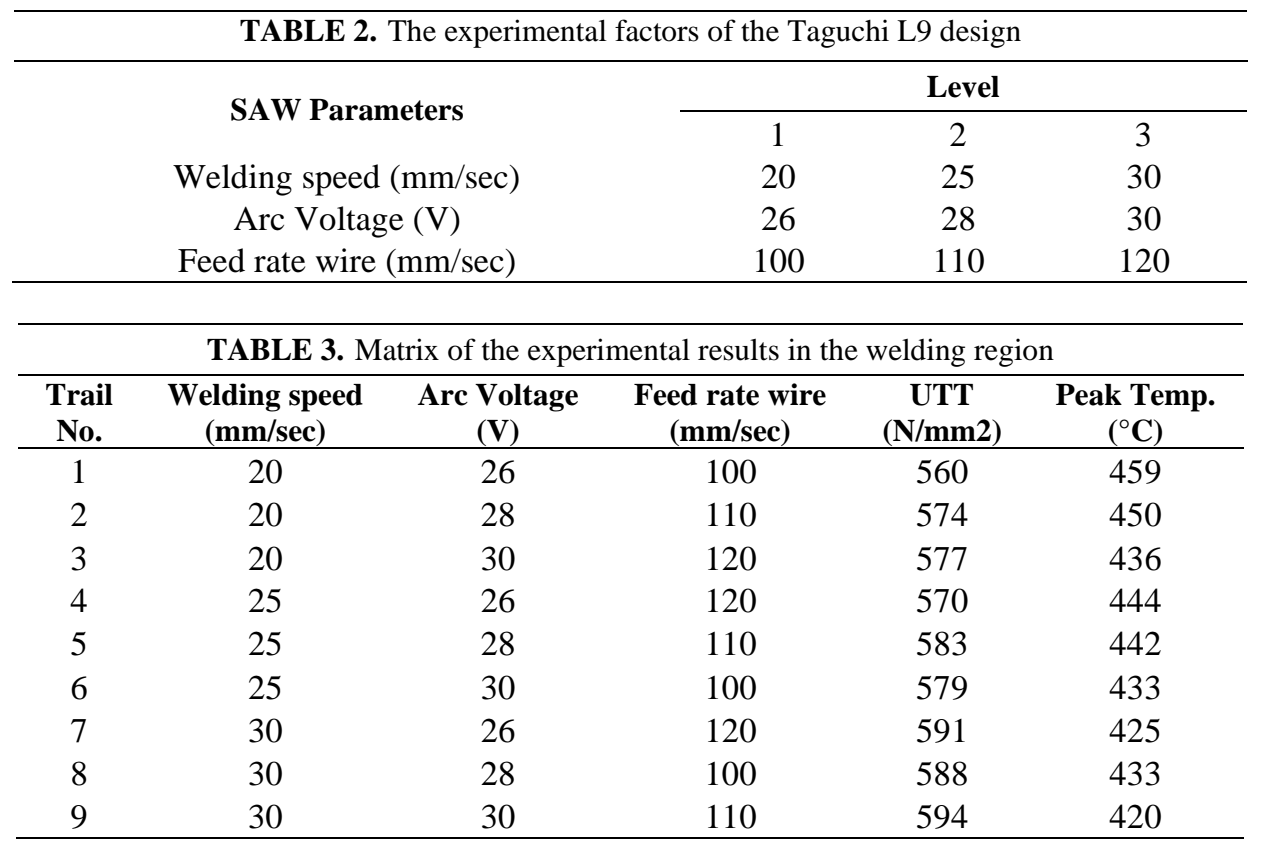




\section{RESULTS AND DISCUSSIONS}

\section{Mathematical Model Development}

Introduced In the current study, the strength of tensile and peak temperature response was expressed as a function of $\mathrm{Y}=\mathrm{f}$ (WS, AV, and WFR) in the welding zone. This mathematical model has been developed using Minitab-17 software with a 95\% confidence level. A Taguchi L9 orthogonal matrix was used according to experimental observations of table 3 to investigate the linear relationship between the outputs (tensile strength and peak temperature) and the input parameters (welding speed (WS), arc voltage (AV), and welding feed rate (WFR)).

The resulted model for tensile strength is:

$$
U T S=416.2+2.067 \mathrm{WS}+2.417 \mathrm{AV}+0.400 \mathrm{WFR}
$$

The peak temperature regression model $(\mathrm{PT})$ is:

$$
P T=625.2-2.233 W S-3.250 A V-0.367 \text { WFR }
$$

ANOVA aims to identify the welding process parameters that affect the design values significantly when the $F$ value is high. Tables 4 and 5 present ANOVA results for the tensile strength and peak temperature. From Table 4, the $\mathrm{P}$-value and F-value of the welding velocity are 0.001 and 55.82, respectively. The welding velocity is considered a significant factor in the welding quality, while the R-square value of tensile strength variance is $93.86 \%$.

Welding speed was found to be a vital parameter in the peak temperature which depends on the minimum $\mathrm{P}$-value (0.002) and the maximum F-value (36.8), as shown in table 5. Finally, the R-square value of the peak temperature

\begin{tabular}{|c|c|c|c|c|c|}
\hline Source & DF & Adj SS & Adj MS & F-Value & P-Value \\
\hline Regression & 3 & 876.83 & 292.28 & 25.46 & 0.002 \\
\hline speed & 1 & 640.67 & 640.67 & 55.82 & 0.001 \\
\hline voltage & 1 & 140.17 & 140.17 & 12.21 & 0.017 \\
\hline Feed & 1 & 96.00 & 96.00 & 8.36 & 0.034 \\
\hline Error & 5 & 57.39 & 11.48 & & \\
\hline Total & 8 & 934.22 & & & \\
\hline \multicolumn{2}{|c|}{$\mathrm{S}=3.3879$} & $\mathrm{R}^{2}=93$. & \multicolumn{3}{|c|}{$R(\operatorname{adj})=90.17 \%$} \\
\hline
\end{tabular}
variance is $91.41 \%$.

\begin{tabular}{lccccc}
\hline \multicolumn{6}{c}{ TABLE 5. ANOVA of peak temperature } \\
\hline Source & DF & Adj SS & Adj MS & F-Value & P-Value \\
\hline Regression & 3 & 1082.33 & 360.78 & 17.74 & 0.004 \\
speed & 1 & 748.17 & 748.17 & 36.80 & 0.002 \\
voltage & 1 & 253.50 & 253.50 & 12.47 & 0.017 \\
Feed & 1 & 80.67 & 80.67 & 3.97 & 0.103 \\
Error & 5 & 101.67 & 20.33 & & \\
Total & 8 & 1184.00 & & & \\
\hline
\end{tabular}

$$
\mathrm{S}=4.50925 \quad \mathrm{R}^{2}=91.41 \% \quad \mathrm{R}(\mathrm{adj})=86.26 \%
$$

The results show the accuracy of the developed models in good agreement with the proposed models. The experimental work strength of tensile and peak temperature is then shown in figure 3. 


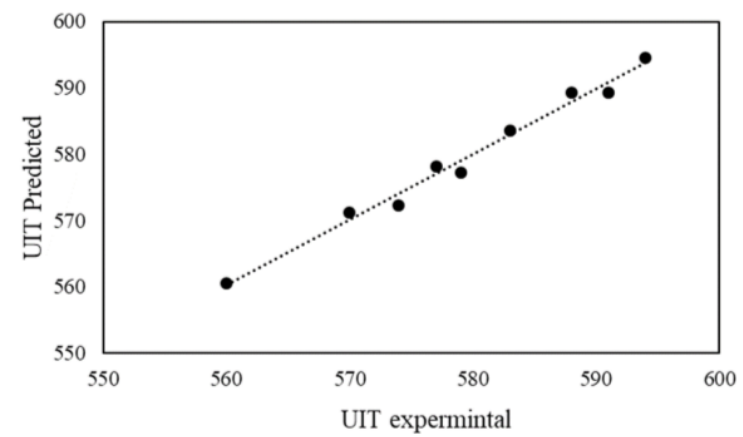

(a)

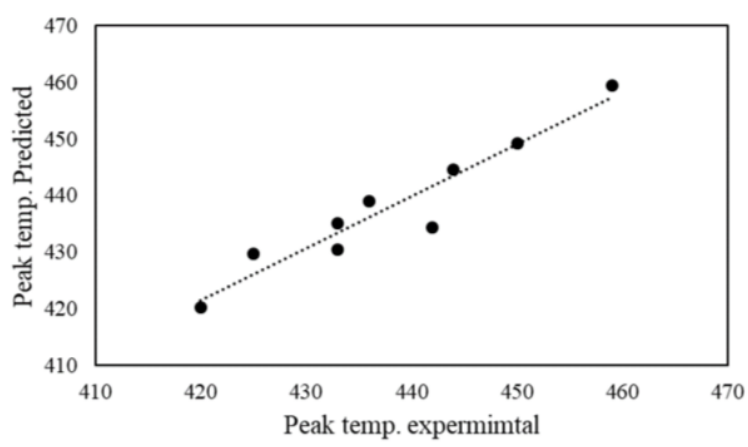

(b)

FIGURE 3. Experimental result against expects results for (a) tensile strength (b) peak temperature.

\section{Peak temperature and Tensile Strength Processes Parameters}

The effect of SAW process parameters on the peak temperature and tensile strength was investigated by testing three data sets. Two parameters were kept at mean values, while the third was raised to the maximum value. The parameter values were investigated according to the regression equations (1) and (2).

Tensile strength: As shown in Figure 4, the results indicate that the tensile strength increased by 3.5\% to $590 \mathrm{MPa}$ when the welding speed varied from 20 to $30 \mathrm{~mm} / \mathrm{s}$. When the voltage changed from 26 and $30 \mathrm{~V}$, the tensile strength increased by $1.45 \%$ up to $583 \mathrm{MPa}$. However, the tensile strength varied from 576 to $584 \mathrm{MPa}$ (about $1.37 \%$ increasing) when the wire feed rate changed from 100 to $120 \mathrm{~mm} / \mathrm{s}$. An increase in the welding speed of $3.5 \%$ was a significant factor influencing the results when compared to the more limited influence of the arc voltage and wire feed rates. These results were matched with ANOVA as indicated in Table 4.

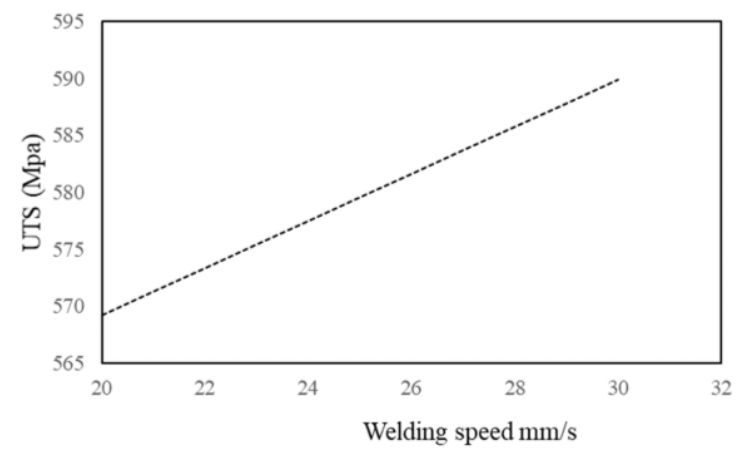

(a)

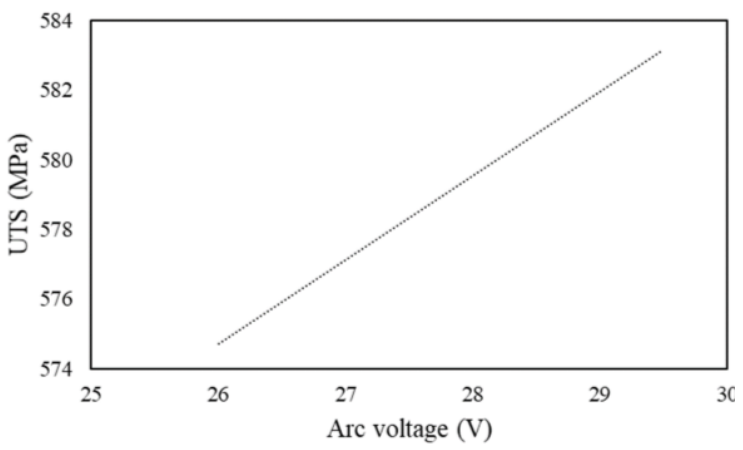

(b)

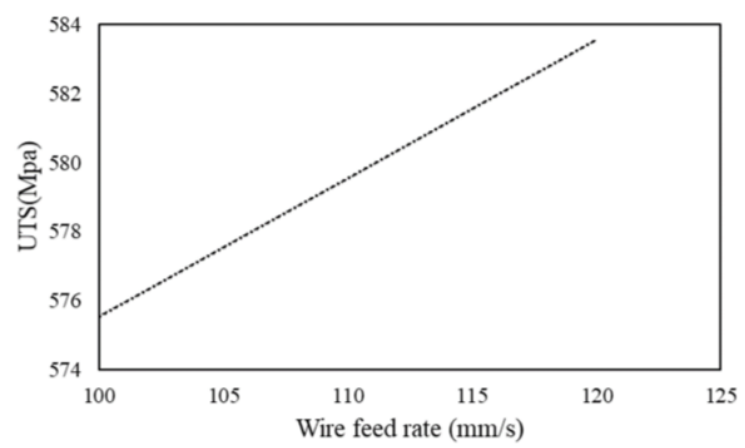

(c)

FIGURE 4. parameters effect on tensile strength a) welding speed b) arc voltage c) feed rate. 
Peak temperature: In Figure 5, when the welding speed changed from 20 to $30 \mathrm{~mm} / \mathrm{s}$, the peak temperature decreased by $4.97 \%$ to $427^{\circ} \mathrm{C}$. The peak temperature decreased by $2.62 \%$ to $433^{\circ} \mathrm{C}$ when the arc voltage changed from 26 to $30 \mathrm{~V}$. When the wire feed rate changed from 100 to $120 \mathrm{~mm} / \mathrm{s}$, the peak temperature then decreased by $1.7 \%$ $\left(434^{\circ} \mathrm{C}\right)$. Again, a decrease in the welding speed (by $4.97 \%$ ) has a significant impact compared to the effect of the arc voltage and wire feed rate. These results are matched with the results obtained by ANOVA as demonstrated in Table 5 .

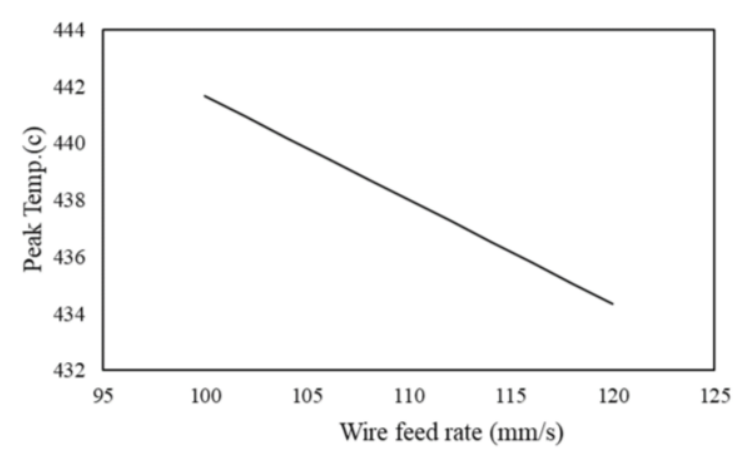

(a)

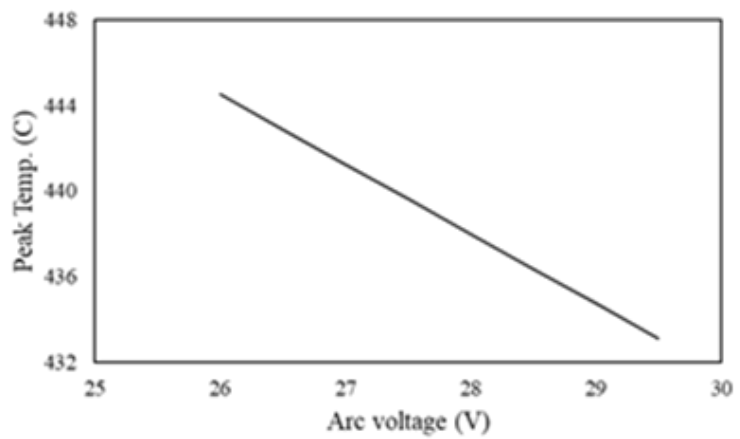

(b)

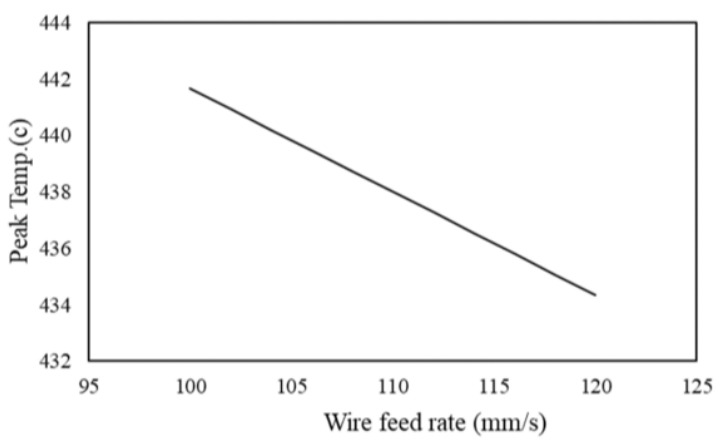

(c)

FIGURE 5. parameters effect on peak temperature a) welding speed b) arc voltage c) feed rate.

\section{Genetic Algorithm}

The study was carried out to establish optimal values for the submerged welding maximum contributing factors of tensile strength and minimum peak temperature in the weld area. The analysis was carried out by the GA toolbox in MATLAB R2010.

The bound ranges of welding speed as following:

The bound ranges of arc voltage

$$
20<W S<30 \mathrm{~mm} / \mathrm{s}
$$

The bound ranges of wire feed rate

$$
26<A V<30 \mathrm{~V}
$$

$$
100<W F R<120 \mathrm{~mm} / \mathrm{s}
$$

The following parameters are used for GA: The optimization toolbox parameters including population sizes 85 , a uniform cross-selection function over a fraction of 0.078 , a homogenous mutation function with an 0.03 mutative rate, and a dispersed crossover function. The maximum number of generations was determined to be 100 . The objective function reached its maximum for tensile strength.

$$
\begin{gathered}
\operatorname{Max} f(x)=[1 /(1+f(W S, A V, W F R)] \\
\operatorname{Max} f(x)=[1 /(1+416.2+2.067 W S+2.417 A V+0.400 W F R)]
\end{gathered}
$$

The objective function can be expressed to reach its minimum for peak temperature. 


$$
\begin{gathered}
\operatorname{Min} f(x)=f(W S, A V, W F R) \\
\operatorname{Min} f(x)=[625.2-2.233 W S-3.250 A V-0.367 W F R]
\end{gathered}
$$

The GA parameters have been obtained for the best solution, as can be seen in Table 6 . The best individual and objective function fitness values for the peak temperature and tensile strength were shown in figure 6.

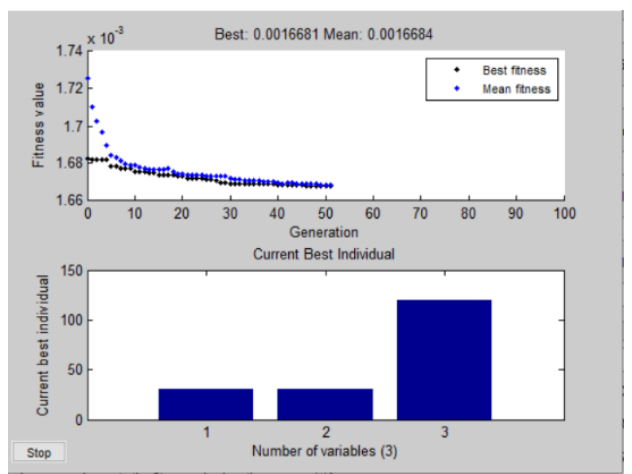

(a)

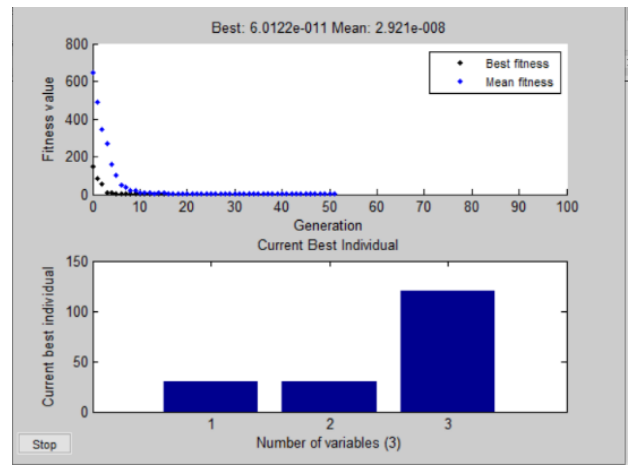

(b)

FIGURE 6. The best individual and fitness values of a) tensile strength and b) peak temperature.

TABLE 6. Optimum of set process parameters

\begin{tabular}{ccccc}
\hline \multicolumn{2}{c}{ Input Parameter } & \multicolumn{3}{c}{ Output parameter } \\
\hline $\begin{array}{c}\text { Welding Speed } \\
(\mathbf{m m} / \mathbf{s})\end{array}$ & $\begin{array}{c}\text { Arc Voltage } \\
(\mathbf{V})\end{array}$ & $\begin{array}{c}\text { Wire Deed } \\
\text { Rate }(\mathbf{m m} / \mathbf{s})\end{array}$ & $\begin{array}{c}\text { Tensile Strength } \\
(\mathbf{M P a})\end{array}$ & $\begin{array}{c}\text { Peak Temperature } \\
\left({ }^{\circ} \mathbf{C}\right)\end{array}$ \\
\hline 30 & 30 & 120 & 599 & - \\
30 & 30 & 120 & - & 417 \\
\hline
\end{tabular}

\section{Simulated Annealing}

As described in the generic algorithm, the SA toolbox in MATLAB R2010 was used to achieve optimization according to the goal function and constraints formulas. The initial configuration for the SA algorithm was the temperature at the first $100^{\circ} \mathrm{C}$, the annealing function of Boltzmann, an interval of $100^{\circ} \mathrm{C}$ for re-annealing, the exponential function for temperature update, and a minor change in the functional equation.

The maximum tensile strength and minimum peak temperature obtained from the SA algorithm are presented in Table 7. Figure 7 demonstrates the fitness function for the tensile strength and the peak temperature reaching a straight line of about 600 and 400 iterations. This figure indicates that there was no transgression of restrictions in each generation. 


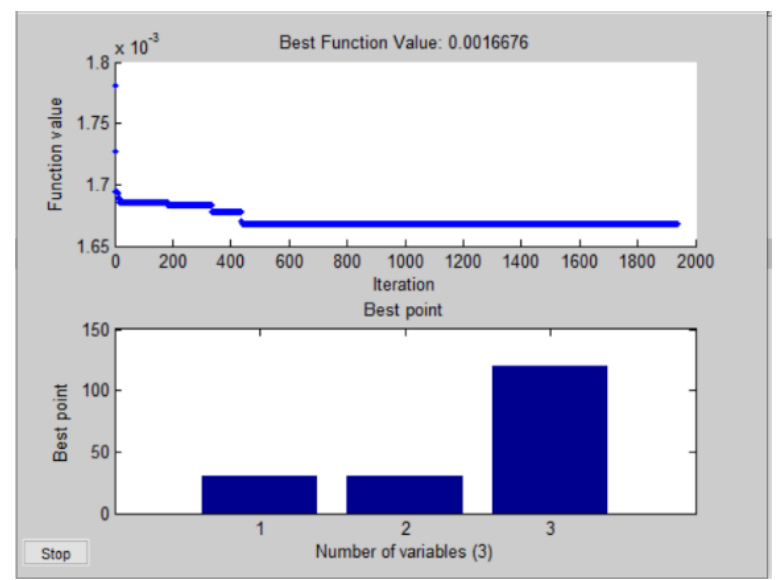

(a)

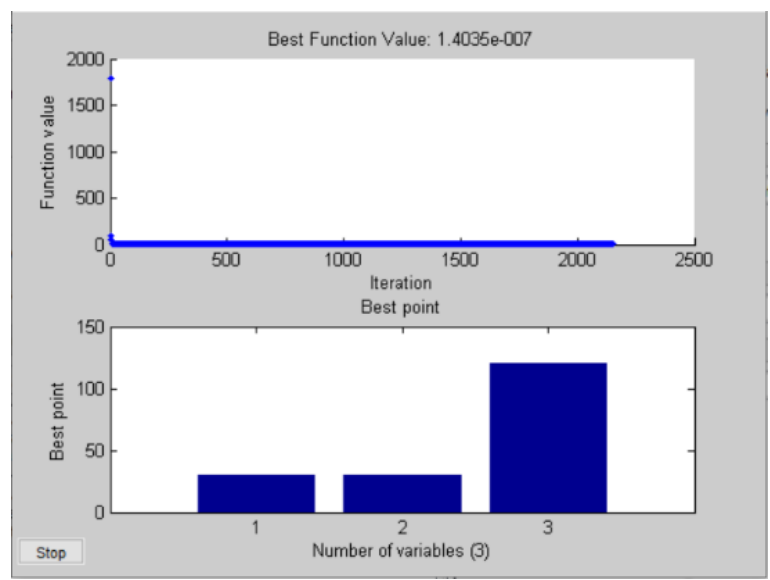

(b)

FIGURE 7. Fitness value of SA function of objective function for a) tensile strength b) peak temperature.

\begin{tabular}{ccccc}
\hline \multicolumn{5}{c}{ TABLE 7. Optimum of set process parameters } \\
\hline \multicolumn{4}{c}{ Output parameter } \\
\hline $\begin{array}{c}\text { Welding Speed } \\
(\mathbf{m m} / \mathbf{s})\end{array}$ & $\begin{array}{c}\text { Arc Voltage } \\
(\mathbf{V})\end{array}$ & $\begin{array}{c}\text { Wire Deed } \\
\text { Rate }(\mathbf{m m} / \mathbf{s})\end{array}$ & $\begin{array}{c}\text { Tensile Strength } \\
(\mathbf{M P a})\end{array}$ & $\begin{array}{c}\text { Peak Temperature } \\
\left({ }^{\circ} \mathbf{C}\right)\end{array}$ \\
\hline 30 & 30 & 120 & 599 & - \\
30 & 30 & 120 & - & 417 \\
\hline
\end{tabular}

\section{Taguchi Method}

The $\mathrm{S} / \mathrm{N}$ ratio has been used as an efficiency scale to identify control levels that perform well in the noise. The $\mathrm{S} / \mathrm{N}$ ratio computes the average (signal) and variance (noise) of the process. It is noted in this analysis that the high S/N ratio is better for the tensile strength, while the low $\mathrm{S} / \mathrm{N}$ ratio is better for peak temperature.

The $\mathrm{S} / \mathrm{N}$ ratios corresponding to tensile strength and peak temperature were presented in Tables 8-9, respectively. The graph for the $\mathrm{S} / \mathrm{N}$ ratio for the strength of tensile and peak temperature is shown in figure 8 . From this figure, it may be concluded that the optimal parameters setting for the maximum and minimum peak temperature are welding speed $=30 \mathrm{~mm} / \mathrm{s}$, arc voltage $=30 \mathrm{~V}$, and wire feed rate $=120 \mathrm{~mm} / \mathrm{s}$, respectively.

\begin{tabular}{|c|c|c|c|}
\hline \multicolumn{4}{|c|}{ TABLE 8. S/N ratios for tensile strength } \\
\hline Level & $\begin{array}{c}\begin{array}{c}\text { Welding speed } \\
(\mathrm{mm} / \mathrm{sec})\end{array} \\
\end{array}$ & $\begin{array}{c}\text { Arc Voltage } \\
\text { (V) }\end{array}$ & Feed rate wire $(\mathrm{mm} / \mathrm{sec})$ \\
\hline 1 & 55.12 & 55.17 & 55.20 \\
\hline 2 & 55.23 & 55.29 & 55.26 \\
\hline 3 & 55.43 & 55.32 & 55.32 \\
\hline Delta & 0.31 & 0.15 & 0.12 \\
\hline Rank & 1 & 2 & 3 \\
\hline \multicolumn{4}{|c|}{ TABLE 9. S/N ratios for peak temperature } \\
\hline Level & $\begin{array}{c}\text { Welding speed } \\
(\mathrm{mm} / \mathrm{sec})\end{array}$ & $\begin{array}{c}\text { Arc Voltage } \\
(\mathrm{V})\end{array}$ & Feed rate wire $(\mathrm{mm} / \mathrm{sec})$ \\
\hline 1 & -53.03 & -52.92 & -52.90 \\
\hline 2 & -52.86 & -52.90 & -52.83 \\
\hline 3 & -52.59 & -52.66 & -52.76 \\
\hline Delta & 0.44 & 0.26 & 0.14 \\
\hline Rank & 1 & 2 & 3 \\
\hline
\end{tabular}




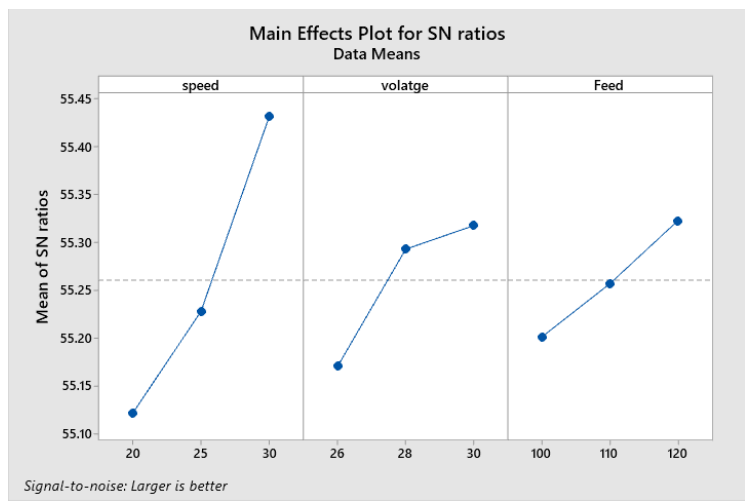

(a)

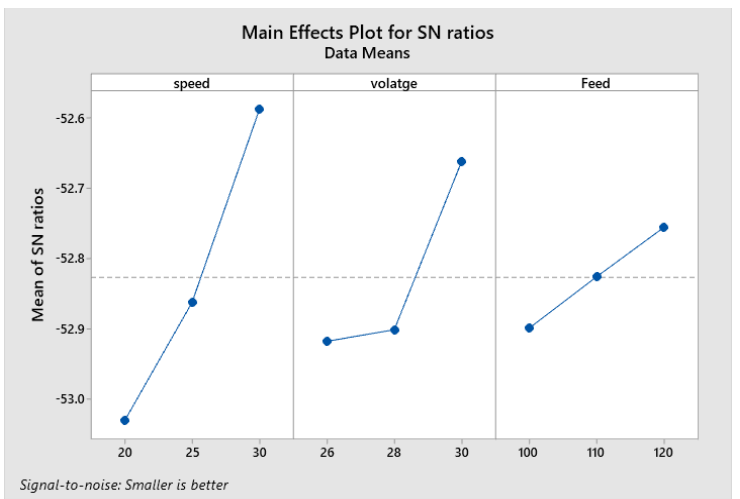

(b)

FIGURE 8. The main of $\mathrm{S} / \mathrm{N}$ ratios for a) tensile strength $\mathrm{b}$ ) peak temperature.

As a summary, despite using three different techniques, but all of them led to similar results where the optimum welding parameters are speed $=30 \mathrm{~mm} / \mathrm{s}$, arc voltage $=30 \mathrm{~V}$, and wire feed rate $=120 \mathrm{~mm} / \mathrm{s}$ with the corresponding ultimate tensile strength of $599 \mathrm{MPa}$ and a peak temperature of $417^{\circ} \mathrm{C}$.

\section{Microstructure Evolution}

A microstructure evolution was conducted to find the microstructure of both sides of AISI 1020, weld metal, HAZ for both sides, and the interface between the base metal and weld metal as shown in figure 9. According to the ASTM E3 standard, the specimens have been subjected to grinding and polishing processes [26]. For microscopic examination, the surfaces of the specimens were prepared by grinding and polishing. Sample treatment was then carried out to obtain an etching of the sample with a ratio of $2 \%$ Natal to obtain its microstructure on the sides of the base metal AISI 1020, weld metal, HAZ for both sides, and the interface between the base metal and the weld metal. After preparation, these examinations were performed with an OLYMPUS optical microscope (GX41).

The microstructure of the plates (of the base metal) consisted of ferrite and pearlite $(\alpha-\mathrm{Fe}+\mathrm{Fe} 3 \mathrm{C})$ to illustrate the effect of the welding process on the metal concerning the microstructure from the area nearest to the HAZ, which explains the effect of the direction of heat flow on the ferrite grains (Figure 9-F). Regarding the Heat Affected Zone (HAZ), figures 9-C and D clearly show the fine structures of this region which contain pearlite and some ferrite.

Most solid-state recrystallization, phase transitions, softening, and tempering, such as grain growth, take place in the HAZ region. The coarse-grained region of HAZ was proximate to the weld fusion area and includes grains bigger than the base mineral (Figure 9-E). Two-phase shifts were then detected in the heat-affected zone during cooling. The first involved the conversion of high temperature from delta to austenite; and the second, the conversion of austenite to ferrite. However, Figure 9 shows that the welding metal center is completely different from other areas. The high cooling rates led to pseudo-granules and inhomogeneity microscopic structure. This area appears to contain pearlite and some ferrite regularly (Figure 9-C and 9-D). Owing to the chemical and temperature gradients that develop during the process, the microstructure that evolved in welding is not homogeneous [27]. Figure 9-E explains how the microstructure of the interface reigns between the base and the metal weld metal. It appears that this zone contains martensite on the base metal side and because of the heat associated with the welding process and rapid cooling, a transformation of austenite into martensite was noted. 


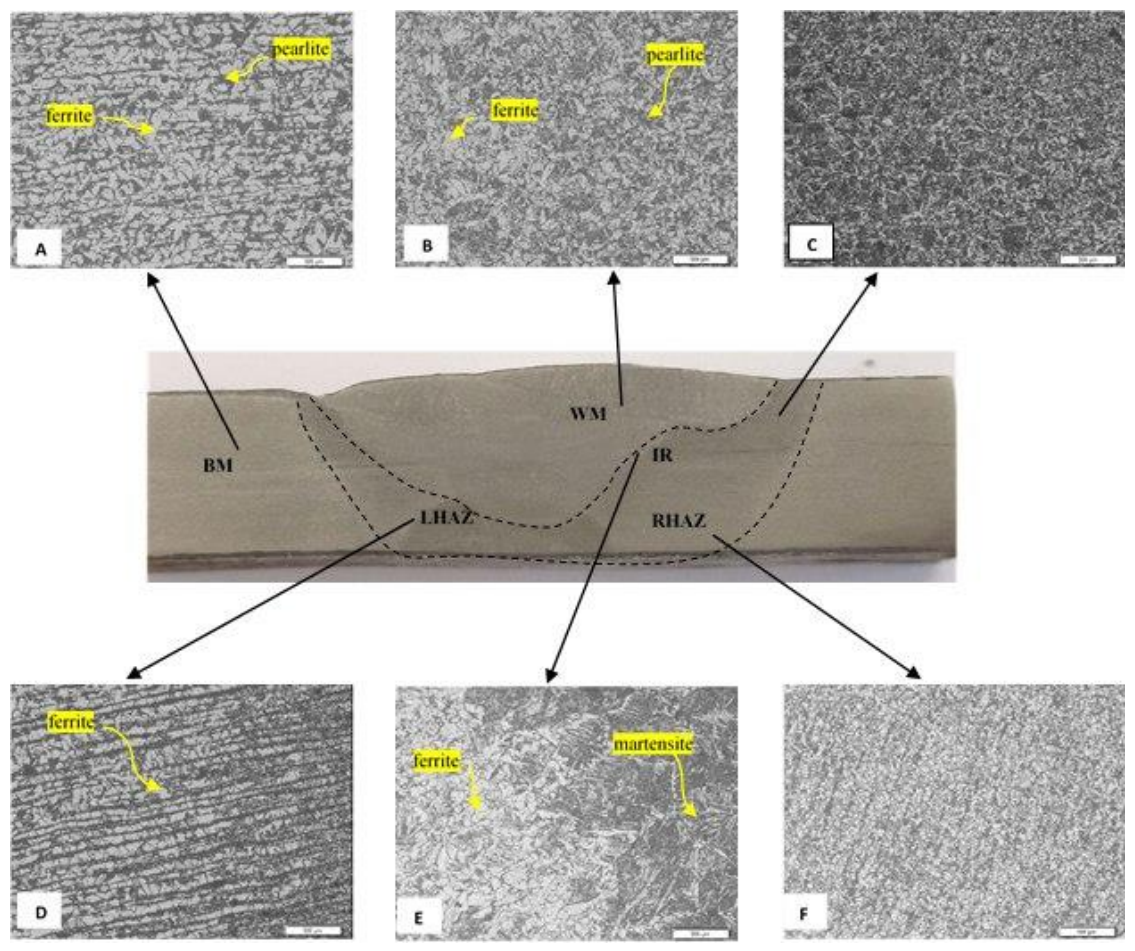

FIGURE 9. Optical images of the microstructure of AISI 1020 high manganese alloy.

\section{Vickers Micro Hardness}

Microstructure hardness was measured from the center of the welded metal to the base material, as shown in Table 10. As anticipated, the weld zone, HAZ, and base metal were observed to have different hardness values. Moreover, the distributions of hardness were generally correlated with the microstructure in figure 9.

The relatively homogeneous microstructure in the seamless materials presented a uniform hardness distribution. The microstructural differences in the weld metal and the HAZ are directly related to the variation obtained with the higher hardness distribution of HAZ. The maximum hardness of $292 \mathrm{HV}$ values was measured in the HAZ region, while the formation of martensite at the weld joint justifies this increase.

The martensite formation generally reduces the steel mechanical properties but increases the hardness value. A complete amorphous iron structure can be achieved if the process conditions were controlled fairly to avoid austenite phase shift [28]. The heating time was prolonged at the weld interface to increase the maximum temperature. This process led to an increase in the axial conduction time of heat to two workpieces and reduced the rate of subsequent cooling [29].

\begin{tabular}{lc}
\hline \multicolumn{1}{c}{ TABLE 10. Vickers micro hardness test results } \\
\hline Case & Average HV \\
\hline Base metal BM & 275.17 \\
Weld metal WM & 250.20 \\
Heat affected zone HAZ & 292 \\
\hline
\end{tabular}

\section{CONCLUSIONS}

Submerged Effective methods were proposed for finding optimal tensile strength and peak temperature in the SAW welding process using a genetic algorithm, simulation annealing, and the Taguchi method. The orthogonal Taguchi 
L9 array was used in this study. The regression models were used with the statistical technique ANOVA to predict the tensile strength and peak temperature at a $95 \%$ confidence level.

The main conclusions of this study can be summarized as follows:

- The optimal parameters setting for tensile strength using genetic algorithm, simulation annealing, and Taguchi were welding speed of $30 \mathrm{~mm} / \mathrm{s}$, arc voltage of $30 \mathrm{~V}$, and a wire feed rate of $120 \mathrm{~mm} / \mathrm{s}$ respectively.

- The tensile strength and peak temperature are more influenced by welding speed than arc voltage and wire feed rate.

- The increase of ultimate tensile strength is proportional to the increase in all the parameters (welding speed, arc voltage, and feed rate), while the opposite occurs at peak temperature.

- This study has presented research on the effect of the SAW welding process on the high manganese alloy AISI 1020. The microstructure was determined at different places of both base and weld metal regions. The microstructure of the weld zone's center differed significantly from that of the heat-affected zone. HAZ contains pearlite and some colonies of ferrite. Clusters of coarse grains grow can be easily observed along with the crystal orientation of preference.

- The maximum hardness of $292 \mathrm{HV}$ values was measured in the HAZ region. The hardness increase can then be explained by the formation of the martensite during the welding process.

\section{REFERENCES}

1. V. Negi and S. Chattopadhyaya, Advan. in Mater. Science and Eng., 2013, 1-9, (2013). DOI:10.1155/2013/543594

2. T. Tadavi, B. Jogi, S. Dhende, S. Banait, and P. Wagh, "Microscopic Analysis of Heat Affected Zone (HAZ) of Submerged Arc Welding (SAW) Joint for 1018 Mild Steel Sheet", (ICCASP International Conference on Communication and Signal Processing 2016), pp. 194-199. DOI:10.2991/iccasp-16.2017.32

3. M. M. Cardona, J. Wongsa-Ngam, H. Jimenez, and T. G. Langdon, J. of Mater. Research and Tech., 6(4), 355360, (2017). DOI:10.1016/j.jmrt.2017.05.002.

4. R. Al-Sabur, A. K. Jassim, and E. Messele, Mater. Today: Proce., 42(5), 2018-2024, (2021). DOI:10.1016/j.matpr.2020.12.253.

5. R. Al-Sabur, M. Slobodyan, S. Chhalotre, and M. Verma, Mater. Today: Proce., 47(17), 5907-5911, (2021). DOI:10.1016/j.matpr.2021.04.431

6. Z. I. Ahmed and A. M. Saadoon, Int J Eng Adv Technol, 5(1), 149-152, (2015).

7. S. Mamunuri, Int. J. of Eng. \& Tech., 7(2.23), 467-471, (2018).

8. B. V. Rao, N. Aravindan, and K. Saraswathamma, Mater. Today: Proc., 5(13), 26961-26967, (2018). DOI:10.1016/j.matpr.2018.08.185.

9. J. Deb Barma, J. Roy, S. Saha, and B. S. Roy, Adv. Mater. Research, 488, 1194-1198, (2012). DOI:10.4028/www.scientific.net/AMR.488-489.1194.

10. P. Sahare and S. K. Pradhan, Int J of Innovations in Eng. \& Science, 3(10), 17-20, (2018).

11. Gupta, S. Datla, C. Sekhar, and N. Ali Shareef, Int J of Mech Eng \& Tech, 9(4), 302-311, (2018).

12. S. Ganguly, S. Datta, and N. Chakraborti, Mater \& Manuf. Proce, 22(5), 650-658, (2007). DOI:10.1080/10426910701323607.

13. P. Sahare and S. K. Pradhan, Mater Today: Proce, 27, 2947-2952, (2020). DOI:10.1016/j.matpr.2020.03.834.

14. J. R. Dhas and S. Kumanan, 11(8), 5198-5204, (2011). DOI:10.1016/j.asoc.2011.05.041.

15. F. Kolahan, A. Tavakkoli, and M. M. Bagheri, "A Genetic Algorithm Approach for Prediction of Process Parameters in Submerged Arc Welding", (37th International Conference on Computers and Industrial Engineering 2007) pp. 1168-1171.

16. H. Tsai, Y. Tarng, and C. Tseng, The Int J of Advan Manuf. Techn, 12(6), 402-406, (1996). DOI:10.1007/BF01186928. 
17. P. Sathiya, S. Aravindan, A. N. Haq, and K. Panneerselvam, Indian J of Eng and Mater Sciences, 13(1), 37-44, (2006).

18. R. Padmanaban, V. Balusamy, V. Saikrishna, and K. G. Niranthar, Procedia Eng, 97, 864-870, (2014), DOI:10.1016/j.proeng.2014.12.361.

19. J. Joseph and S. Muthukumaran, The Int J of Advan. Manuf. Techn., 93(1), 23-34, (2017). DOI:10.1007/s00170015-7599-8.

20. E. Ginting and M. Tambunan, Mater. Sci, and Eng, 288(1), 1-6, (2018). DOI:10.1088/1757-899X/288/1/012056.

21. A. Asmare, R. Al-Sabur, and E. Messele, Metals, 10(11), 1480-1521, (2020). DOI:10.3390/met10111480.

22. J. H. Holland, "Adaptation in natural and artificial systems: an introductory analysis with applications to biology, control, and artificial intelligence", (MIT press, 1992).

23. X.-S. Yang, "Nature-inspired optimization algorithms", (Academic Press, 2020).

24. M. Miki, T. Hiroyasu, and K. Ono, "Simulated annealing with advanced adaptive neighborhood," (Second international workshop on Intelligent systems design and application, 2002) pp. 113-118.

25. O. Erdinc, "Optimization in renewable energy systems: recent perspectives", (Butterworth-Heinemann, 2017).

26. ASTM E3-01: "Standard Guide for Preparation of Metallographic Specimens", (ASTM 2009).

27. O. Grong, "Metallurgical modelling of welding. Institute of Materials", (Carlton House Terrace, London, 1997).

28. C.-P. Cheng, H.-M. Lin, and J.-C. Lin, Sci and Tech of Weld and Join, 15(8), 706-711, (2010). DOI:10.1179/136217110X12785889549507.

29. T. Nguyen and D. Weckman, Metall. and Mater. Trans B, 37(2), 275-292, (2006). DOI:10.1007/BF02693157. 